\title{
USE OF WIRIS QUIZZES IN AN ONLINE CALCULUS COURSE
}

\author{
Remei Calm ${ }^{1}$ D, Ramon Masià ${ }^{2}$, Carme Olivé ${ }^{(D)}$, Núria Parés ${ }^{4}$ iD, Francesc Pozo ${ }^{4}$, \\ Jordi Ripoll $^{1}$ (iD), Teresa Sancho-Vinuesa ${ }^{2}$ iD \\ ${ }^{1}$ Departament d'Informàtica, Matemàtica Aplicada i Estadística, Universitat de Girona (Spain) \\ ${ }^{2}$ Computer Science, Multimedia and Telecommunication Studies, Universitat Oberta de Catalunya \\ (Spain) \\ ${ }^{3}$ Departament d'Enginyeria Informàtica i Matemàtiques, Universitat Rovira i Virgili (Spain) \\ ${ }^{4}$ Escola d'Enginyeria de Barcelona Est (EEBE), Universitat Politècnica de Catalunya (UPC) (Spain)

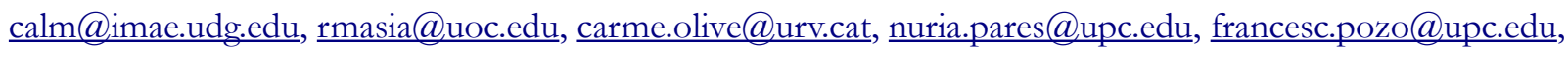 \\ jripoll@imae.udg.edu, tsancho@,uoc.edu
}

Received November 2016

Accepted April 2017

\section{Abstract}

Calculus courses often present a large number of difficulties to undergraduate students of scientific studies, especially in engineering degrees. These difficulties are sometimes related to teaching and assessment strategies. In this paper, a teaching innovation experience is presented within the framework of the Universitat Oberta de Catalunya. This teaching experience is focused on a continuous assessment through a systematic use of the so-called WIRIS quizzes. Academic outcomes are very positive from both quantitative and qualitative viewpoints.

Keywords - Assessment tools, Online calculus, Continuous activity. 


\section{Introduction}

Generally speaking, mathematics courses often pose severe difficulties to engineering undergraduates: the dropout rate is high and performance is low. A varied range of approaches have been used to facilitate the development of teaching innovation projects, with varying levels of success. In 2007, the mathematics academic staff in the Universitat Oberta de Catalunya's (UOC) undertook a review of teaching strategies and proposed a series of improvements aimed at improving the learning experience and achieving better academic results. The first step was to review and update the study materials (Sancho-Vinuesa \& Masià, 2007) and develop specific applications for online learning environments (Sancho-Vinuesa \& Gras-Martí, 2010; EscuderoViladoms \& Sancho-Vinuesa, 2010). Specifically, online study material was developed for the introductory course 'Introduction to mathematics for engineering', which includes videos, simulations, text documents, activities and links to relevant resources. Although the results could have been better in the area of course follow-up, the success achieved in its application led us to reflect on the methodological strategy and the assessment system, approaching the issue from three directions. First, reflecting on the assessment process as the cornerstone of the teaching and learning process; second, reducing the dropout rate; and, lastly, improving the students' academic performance in the UOC's mathematics courses.

A number of elements play a key role in the teaching strategy for online mathematics: on the one hand and assuming that the learning resources are sufficient, activity planning and feedback; on the other hand, the assessment as the cornerstone of teaching and learning activity (Himmel, 2011). Taking all the latter into account, a methodology based on continuous activity and instant feedback was considered, with the formative assessment as a key part of the learning process.

Exploring different tools that could meet the expectations led us to the WIRIS quizzes application, developed by the Maths for More software firm. WIRIS quizzes is the questionnaire tool for Moodle, enriched with the WIRIS calculator, which enables mathematical expressions to be written and interpreted, and mathematical questions to be generated with random parameters. Very encouraging results were obtained in the introductory course 'Introduction to mathematics for engineering' (Escudero-Viladoms \& Sancho-Vinuesa, 2016). 


\section{A new teaching strategy: Continuous activity and feedback}

The new teaching strategy has now been applied to two mathematics courses included in the degrees offered by the Faculty of Computer Science, Multimedia and Telecommunications of the Universitat Oberta de Catalunya's (UOC). The two courses analysed are 'Calculus', for the Bachelor's Degree in Computer Engineering (A in the graphs), and 'Mathematics II', for the Bachelor's Degree in Telecommunications Technology ( $\mathrm{M}$ in the graphs).

They are different courses but its teaching strategy is identical, as also is the assessment strategy. Although content overlap is $70 \%$, the study materials are developed by the same team of authors and, therefore, the approach, nomenclature and style are identical.

The outcomes of these courses have been analysed over a nine-semester period, from March 2011 to September 2015. During this period, it is possible to identify two clearly differentiated teaching methodologies, used in different semesters. During the first seven semesters, from March 2011 to July 2015, the UOC's traditional strategy was applied, based on a continuous assessment (CA) focused on the completion of traditional (normally four) continuous assessment tests (called CAT). These tests have long completion deadlines (at least two weeks), long gaps between CATs (at least two weeks), delayed feedback (at least one week) and a very small number of tests. During the last two semesters, from September 2014 to July 2015, the new strategy was applied, based on carrying out introductory Moodle exercises and a learning/assessment methodology with (mostly) self-correcting interactive questionnaires. This was supported by a generally automatic and immediate feedback, with short completion deadlines (maximum two days) and taken at frequent intervals (a total of nine tests were given during the last semester), in addition to the prior practice runs with the same tool. The study materials for the first two modules of the course were also updated with the inclusion of Moodle exercises.

Specifically, we propose two sort of questionnaires, the first one where students can practice the exercises of each topic (PQ) and the second one that is the evaluation task itself (AQ).

The PQ is made up by 10 exercises of different types like multiple choice questions or open questions (the answer is a numerical value or even a mathematical function), as can be seen in Figure 1. The number of attempts allowed is unlimited and each new execution generates similar exercises but with different parameters. 


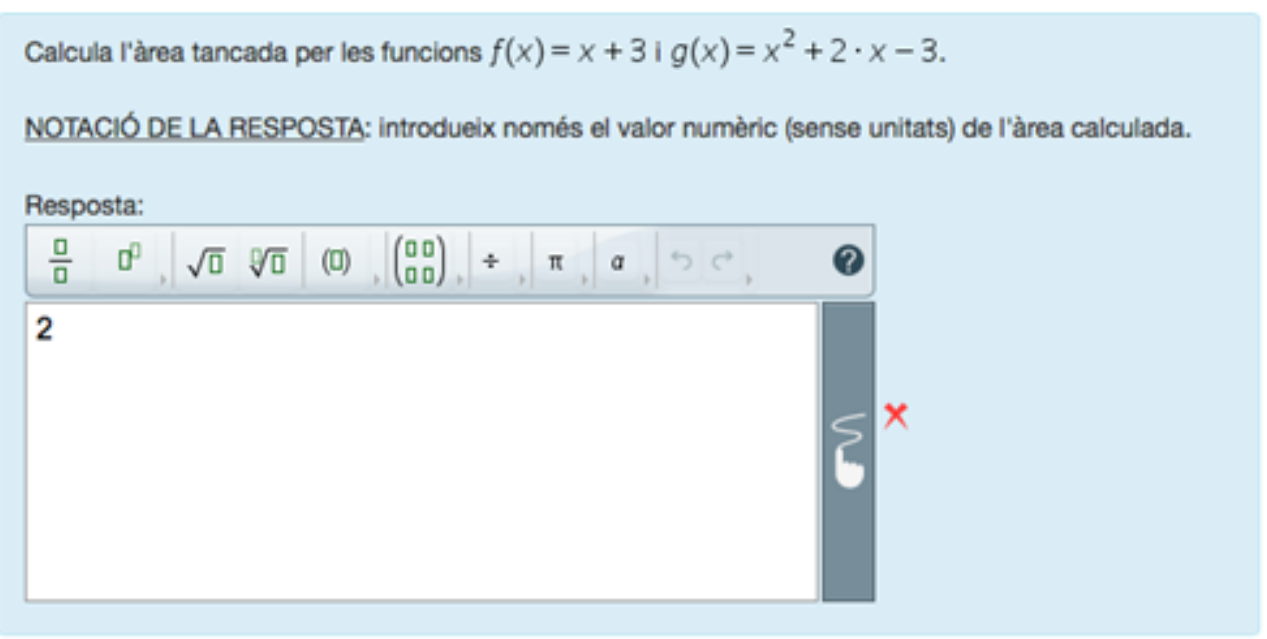

Figure 1. Example of a question of PQ on the topic of definite integrals and areas of regions

Once the answers are submitted by the students, they receive feedback including the correct answer as well as the specific resolution, see Figure 2.

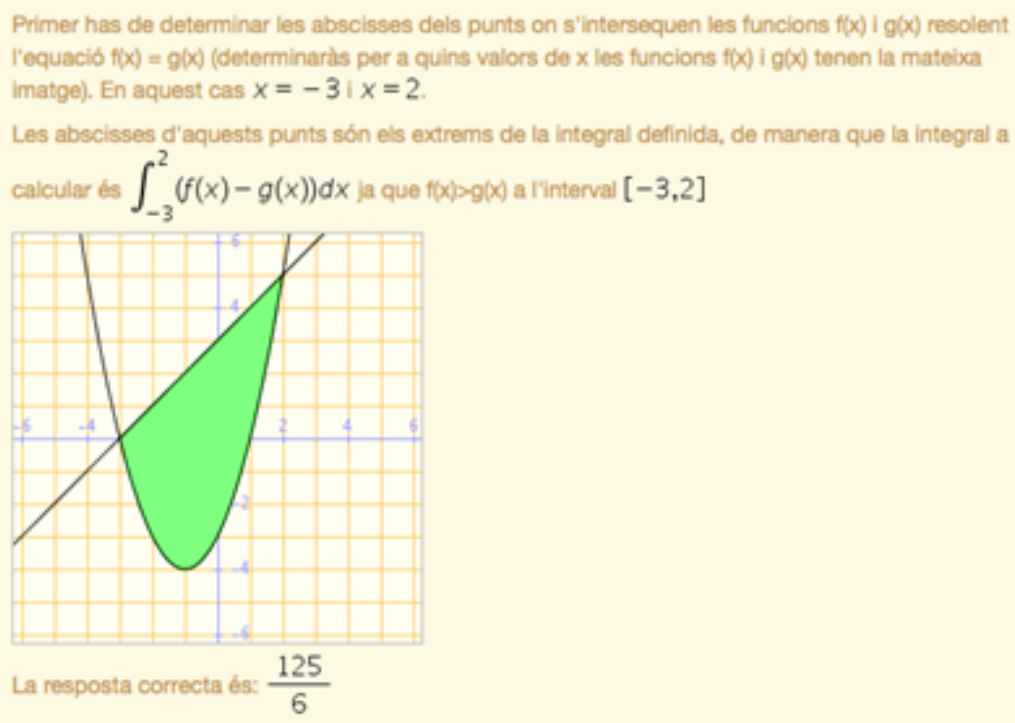

Figure 2. Feedback for the question shown in Figure 1 
Regarding the AQ, they are structured in five questions of the same kind as in PQ where the answers are automatically corrected, plus an additional question of open-answer format where students have to develop the procedure to the given answer. The staff of teachers corrects each final question manually. Since this questionnaire is an assessment task, students only have one attempt and they receive feedback, of the same type as in the PQ, just after the questionnaire is closed and sent.

The same assessment model was applied during the entire period analysed, with a final on-site examination whose mark contributes $70 \%$ of the final assessment.

\section{Analysis of the results}

The results concerning participation and success in the continuous assessment questionnaires have been analysed quantitatively and a number of elements have been identified that account for the interest offered by this tool and its effective use.

Firstly, a significant increase is observed in the number of students taking and passing the continuous assessment. The number of students taking the continuous assessment increased notably in the last two semesters, standing at $15 \%$ above the total course average (the red line in Figure 3), while in most of the other semesters, it is below the average. 


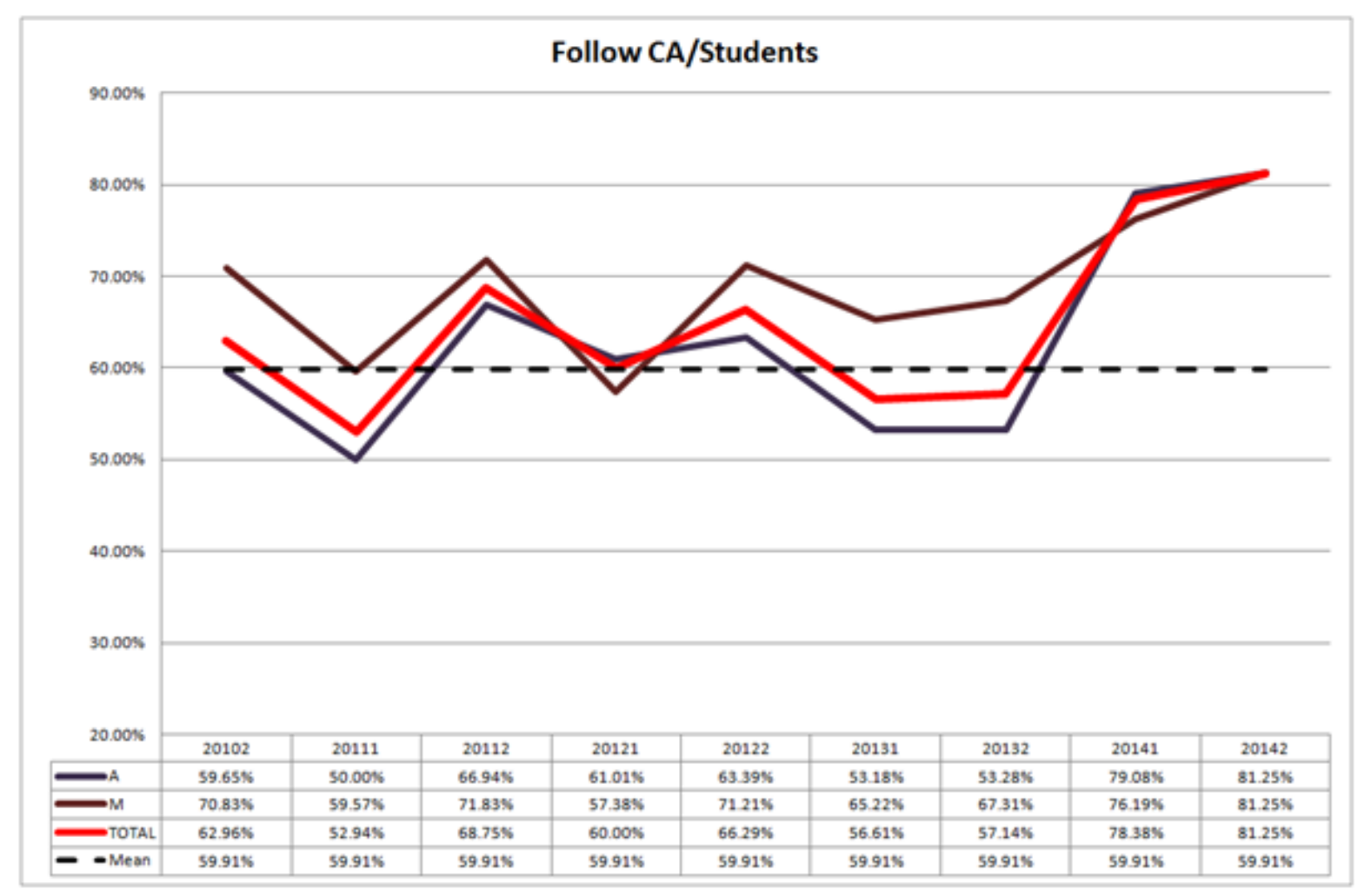

Figure 3. Students on continuous assessment with respect to the total number of students

Secondly, there is a significant increase in the number of students who pass the course. In the last two semesters, the number of students who pass is $8 \%$ above the average in each semester (the red line in Figure 4), while in the other semesters, except for one (the second semester of the year $2013 / 2014,20132)$, the pass rate is below the average. 


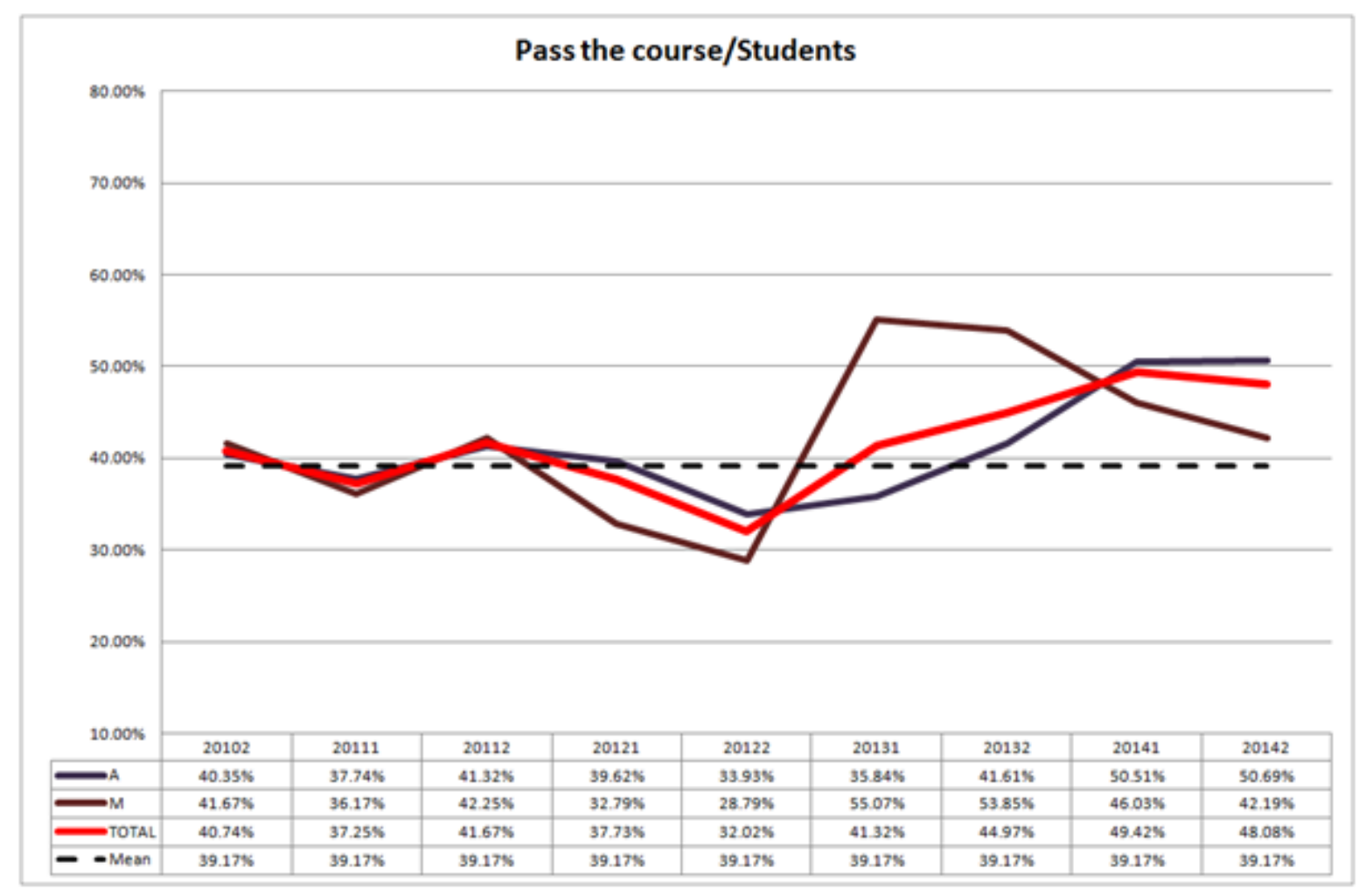

Figure 4. Students passing the course with respect to the total number of students

Thirdly, a slight increase is detected in the ratio of students who pass the course with respect to the number of students who take the exam (the red line in Figure 5). This ratio is only exceeded in one prior semester (20132). Furthermore, even though the number of students taking the exam in the last two semesters is higher than in previous semesters, this increased number has not reduced the overall success rate. 


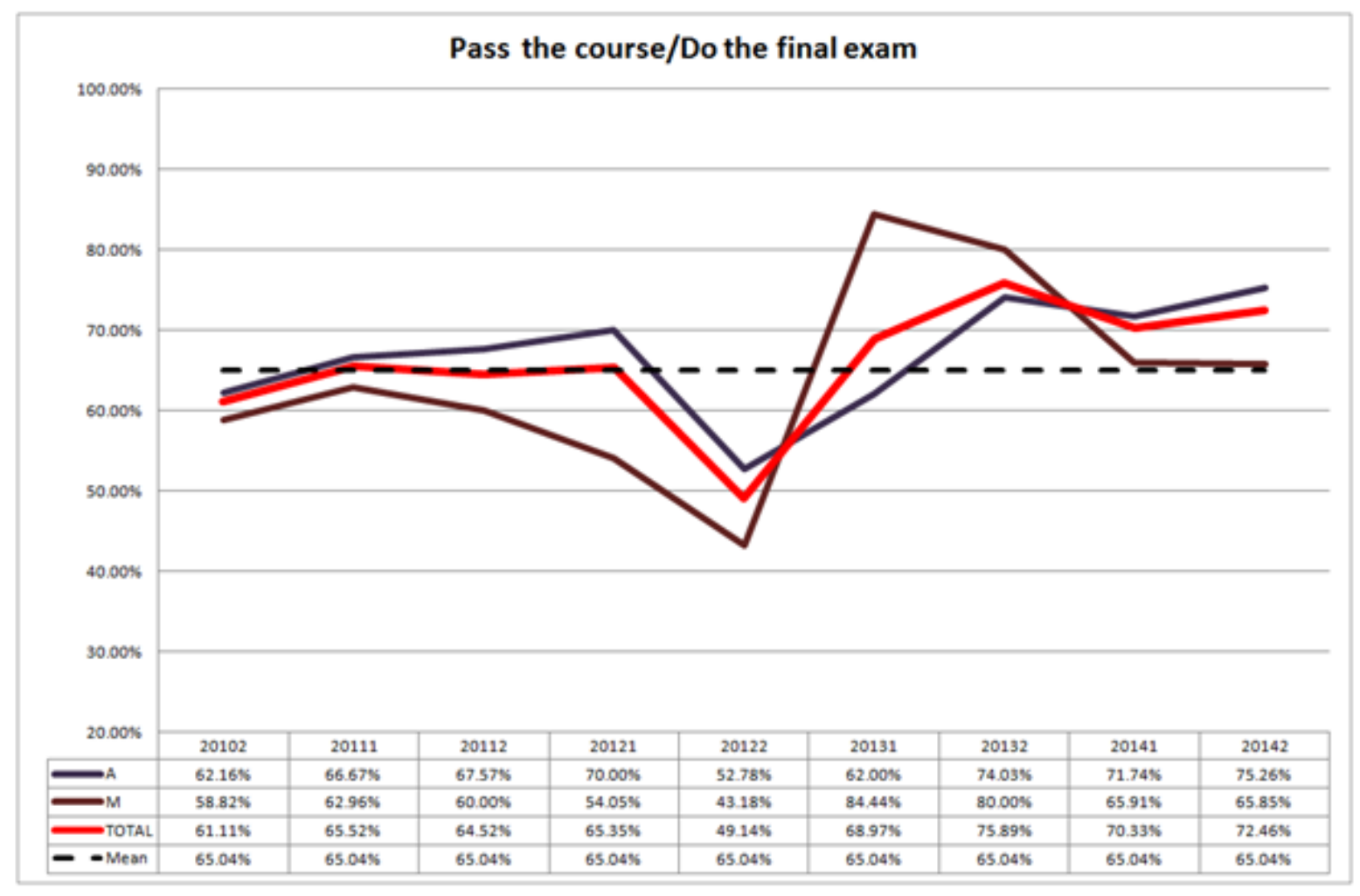

Figure 5. Students passing the course with respect to the total taking the final examination

From a qualitative viewpoint, both students and teachers have a very positive perception of the new strategy. According to the results of the institutional survey given to students and which has a response rate of about $15 \%$, the levels of satisfaction with the new strategy are, generally speaking, higher than in previous semesters. In their remarks, they say that the increase in their dedication to study is made up for by the results obtained. The faculty has worked hard on developing and implementing the new materials; their perception of the materials has also been very positive, because they have seen that with the new system, their teaching is now more effective and creative: administrative and repetitive tasks have been gradually diminishing. 


\section{Conclusions and future lines of research}

The design and implementation of the study materials and assessment strategies for the calculus courses in the UOC's engineering degrees have always focused on improving the quality of our students' learning.

A new formative assessment paradigm, based on continuous activity with immediate feedback through exercises and WIRIS quizzes, has been shown to be effective in improving the students' final results in an online course of Calculus. Likewise, both students and faculty staff involved also seem to show greater satisfaction with these courses. In this sense, in future works we will take a survey of satisfaction to the students and teachers in order to analyze their experience about them.

The results of this experience encourage us to continue developing this teaching methodology and to closely observe its use in the virtual classrooms. This requires performing further in-depth studies of the effectiveness of the regular use of questionnaires with automatic assessment for the follow-up and assessment of students enrolled on online engineering degree courses.

\section{References}

Escudero-Viladoms, N., \& Sancho-Vinuesa, T. (2010). Educational Social Software for ContextAware Learning: Collaborative Methods and Human Interaction. In Analysis of interactions through a web annotation tool in a pre-university mathematics online course (pp. 79-97). IGI Global..

Escudero-Viladoms, N., \& Sancho-Vinuesa, T. (2016). Confidence and learning: Affective and cognitive aspects in online mathematics with automatic feedback. In Santi Caballé and Robert Clarisó (ed.), Formative Assessment, Learning Data Analytics and Gamification in ICT Education. Elsevier: Academic Press. https://doi.org/10.1016/B978-0-12-803637-2.00005-1

Himmel, E. (2011). Evaluación de aprendizajes en la educación superior: Una reflexión necesaria. Pensamiento Educativo. Revista de Investigación Educacional Latinoamericana, 33(2), 199-211.

Sancho-Vinuesa, T., \& Masià, R. (2007). A virtual mathematics learning environment for engineering students. Interactive Educational Multimedia, 14, 1-18. 
Sancho-Vinuesa, T., \& Gras-Martí, A. (2010). Teaching and learning undergraduate mathematics in an online University, published in Educational Technology in Practice: Research and Practical Case Studies from the field (pp. 145-152). Information Age Publishing Inc.

Published by OmniaScience (www.omniascience.com)

Journal of Technology and Science Education, 2017 (www.jotse.org)

Article's contents are provided on an Attribution-Non Commercial 3.0 Creative commons license. Readers are allowed to copy, distribute and communicate article's contents, provided the author's and JOTSE journal's names are included. It must not be used for commercial purposes. To see the complete licence contents, please visit http://creativecommons.org/licenses/by-nc/3.0/es/ 